\title{
D.F.M. Straus
}

DIE SKRIF:

DIE LIG VIR ALLE WETENSKAPPE

\section{Inleiding}

Die kernvrae van hierdie tema sentreer rondom die aanduidinge: 'die lig van die Skrif' en 'alle wetenskappe'. Daarom begin ons met enkele opmerkinge oor die aard van die Skrif-lig en vervolg dan met 'n besinning oor die betekenis daarvan vir die wetenskap.

\section{Biblisistiese siening van Skrif-lig ontoereikend}

Met die term „biblisisme” wil ons hier verwys na dáárdie opvatting wat meen dat die gesag van die Bybel slégs gehandhaaf kan word indien daar in die Bybel direkte uitsprake oor elke moontlike Christelike aktiwiteit gevind kan word - dergelike Skrifgegewens word maklik bestempel as Skrifbegin sels vir die volle lewe van die mens.

In onderskeiding van die egte Roomse Skolastiek (wat die verlossing in Christus afgeperk het tot die kerk as instituut) lê daar aan hierdie opvatting 'n Gereformeerd-skolastiese instelling ten grondslag wat nog in navolging van Aristoteles (Metaf. 996) en Thomas (weliswaar soms slegs implisiet) die teologie verhef tot 'koningin van die wetenskap' waardeur die 'rede' van die mens 'gebind' word aan die 'lig van die Skrif' deurdat die teoloog die 'Skriftuurlike beginsels' moet lewer waaraan die nie-kerklike en nie-teologiese aktiwiteite van die mens hulle moet oriënteer. Waar die Skolastiek die 'lig van die Skrif' binne die donker mure van die Roomse Kerk vasgepen het, het die Gereformeerde skolastiek (om Kuyper aan te haal) die 'vensters oopgemakk sodat die Tamp deur Christelijke religie' op al die 'geledingen van ons menschelijk leven' gewerp kan word (De Gemeene Gratie, 3de druk, Vol. II p. 272).

Hierdie biblisisties-verskraalde siening van die lig van die Bybel (dikwels ondersteun deur 'n kerk-sentrisme of minstens 'n kerk-sentriese visie op die roeping van die Christen) is juis op die terrein van die wetenskap opvallend ontoereikend. Daar bestaan immers vandag dissiplines waaroor nòg direk, nòg indirek binne die konteks van sekere Bybeltekste enige inhoudelike in sig of onderskeiding na vore gebring kan word. In sulke gevalle is daar slegs 'n algemeen-grondleggende Bybelse appèl moontlik - waarop ons egter aan- 
stons terugkom. Dink slegs aan dissiplines soos die algemene sisteem-teorie, die sibernetika of die biochemie - en u sal spoedig besef dat sogenaamde direkte Skrifberoep hier geen hulp sal bied nie. In die praktyk kom die biblisistiese 'program' dan ook slegs daarop neer dat bepaalde sake waaroor die Bybel wél een en ander sê, uitgelig word, terwyl al dié sake waaroor daar geen direkte aanwysinge in die Skrif gevind word nie, rustig gelaat word binne die breë natuurlike sfeer van die mens se 'gesonde verstand' (behorende tot die terrein van die 'algemene genade'). Indien die gesag van die Skrif werklik afhanklik was van direkte uitsprake oor elke saak waarmee die Christenmens, ook in die wetenskap, te doen kan kry, sal juis hierdie uitgangspunt direk daartoe aanleiding gee dat die werklike lewensomvattende gesag van die Bybel totaal ondergrawe word. Vóórdat derhalwe na vermeende Skrifgegewens gekyk kan word wat veronderstel is om vir hiérdie of dáárdie prinsipiële riglyne te bied, moet allereers besin word of hierdie metodiek hoegenaamd aangewend mag word - altans indien erns gemaak wil word met die universele strekking van die Bybelboodskap!

\section{'n Radikaal-Bybelse instelling in die wetenskap}

'n Egte Bybels-reformatoriese visie moet deurdring tot die lig wat Gods lewendmakende Gees in die wortel van die mens se bestaan ontsteek deur Christus se verlossingswerk, en wat vanuit daardie worteldiepte alle lewensektore (nie slegs sydelings vanuit die kern en/of teologie nie, maar radikaal en integraal) deurlig, sodat die Christenmens sy volle lewe kan laat opbloei in die verheerliking van God Drie-enig. Die 'lig van die Skrif' beteken dan die beligting van die mens se hart deur die sentrale en totale appèl van Gods Woord wat, as rigtinggewende dryfkrag, sy volle lewe in Christus tot eer van God laat ontplooi, gehoorsaam aan die wil van God - die diens van God met die héle hart.

Hierdie sentrale, op God gerigte ingesteldheid wat die Bybel ook aan ons wetenskaplike denke verskaf, los geensins vanself enige intrinsiek-wetenskaplike probleem op nie - indien dit immers wél die geval sou wees, sou Christelike wetenskap slegs bestaan het uit geldige logiese deduksies uit bepaalde (relevantgeagte) Skrifgegewens. Die sentrale appèl van die Bybel open veeleer aan ons verskeie sentrale perspektiewe, waaronder die insig dat ook die menslike wetenskaplike denke begrond word deur die orde van Gods skepping en derhalwe gehoorsaam behoort te wees aan die skeppingsgegewe eise wat vir die wetenskap geld. Op hierdie punt moet ons egter eers kortliks stilstaan by die tipiese aard van die wetenskap. 
Wat is die onderskeidende kenmerk van wetenskap?

Hierdie vraagstelling stel nie belang in al dié kenmerke van wetenskap wat ook aanwesig is by nie-wetenskaplike aktiwiteite nie (soos sistematiek, metodologie, verifikasie/valsifikasie, en so meer), want dit wil rekenskap probeer gee van dit wat wetenskap onderskei van nie-wetenskap.

Wetenskaplike denke is 'n bepaalde soort analities gestempelde aktiwiteit. Analise is ' $n$ subjektief-logiese handeling wat ondermeer bepaal word deur die logiese norme van identiteit en teëspraak. In die lig van hierdie normbepaaldheid kan analise bestempel word as identifiserende onderskeiding (of: onderskeidende identifisering). Analise veronderstel egter skeppingsgegewens wat identifiseer-baar en onderskei-baar is (dit wil sê gegewens wat logies objektiveerbaar is - waar logiese objektivering natuurlik altyd 'n subjektief-logiese aktiwiteit is).

Die besondere (onderskeidende) aard van wetenskaplike analise dui ons aan deur te sê dat wetenskap gesien moet word as modaal-abstraherende analise. In elke analitiese aktiwiteit (wat ingeweef is in logiese objektivering) kán daar gekom word (dit hoef natuurlik nie noodwendig te gebeur nie) tot 'n 'konkrete' of 'n modale abstrahering (afsien van). 'n Klein kindjie wat vir die eerste keer 'n duif sien, kan reeds konkreet abstraheer, byvoorbeeld wanneer hy 'n paar dae later na 'n mossie verwys as 'n duif. Hy dui dan die begrip voèltjie aan met die naam ,duif" - iets wat alleen moontlik is deurdat die kindjie uit die konkrete sintuiglike waarnemingsbeeld van 'n duif sekere tipiese voël-kenmerke geabstraheer het (byvoorbeeld 'n snaweltjie, pootjies, vlerke, vere) en tegelyk daarmee afgesien het van die spesifieke kenmerke van ' $n$ duif in onderskeiding van ' $n$ mossie. Hierdie tipe abstrahering betref egter nie die onderskeidende kenmerk van wetenskap nie, want daagliks verskyn sulke konkrete abstraherings in allerlei vorme van niewetenskaplike begripsvorming (dink slegs aan begrippe soos: plant, dier, mens, gereedskap, en so meer).

Eers wanneer gekom word tot die abstrahering van 'n modale aspek (wat dan geidentifiseer en onderskei word, dit wil sê logies geobjektiveer word), ontmoet ons egte teoreties-logiese (dit is modaal-abstraherende) denke, wat tegelyk die toegangspoort bied tot 'n teoretiese analise óók van die tipiese totaalstrukture van individuele dinge, gebeurtenisse of samelewingsverhoudinge. (Laasgenoemde entiteite besit trouens almal individuele subjeks-, respektiewelik subjeks- en objeksfunksies in alle werklikheidsaspekte.)

Met die woord aspek word hier, in aansluiting by die tradisie in die reformatoriese wysbegeerte, gedui op 'n grondleggende bestaanswyse (modus 
quo) wat nooit vereenselwig mag word met enige konkreet-individuele entiteit wat bloot in die verskillende bestaanswyses (modaliteite) funksioneer nie. Nie-wetenskaplike denke is altyd (nie-modaal-abstraherend) gerig op die alsydigheid van konkrete gegewens. In hierdie konkreet-alsydige ervaring is die modale funksies van dit wat ervaar word sekerlik geimpliseer, maar beslis nog nie as sodanig (modaal) geabstraheer nie. Wanneer ons 'n duur motor opmerk, ervaar ons die ekonomiese aspek aan en in die waargenome motor sónder om oor te gaan tot die (modaal-abstraherende) ontwikkeling van 'n ekonomiese prysteorie! Net so ervaar ons die getalsaspek aan en in die hoeveelheid mense of diere wat ons opmerk, sonder om enigsins oor te gaan tot die abstrahering van hierdie aspek.

\section{Veronderstellinge in die wetenskap}

Uit die aard van wetenskaplike denke as teoreties-logiese (modaalabstraherende) denke vloei belangrike konsekwensies voort. Ons het reeds opgemerk dat alle analise skeppingsgegewens veronderstel wat analiseerbaar (dit is identifiseerbaar en onderskeibaar) is. Analise veronderstel derhalwe 'n meer-as-logiese skeppingsverskeidenheid. Wie gevolglik wetenskap beoefen, word kragtens die struktuur van wetenskaplike denke verplig om (implisiet of eksplisiet) rekenskap te gee van die gegewe analiseerbare skeppingsverskeidenheid, en wel in die vorm van een of ander teoretiese samehangsvisie op die gemelde verskeidenheid.

Om egter sinvol rekenskap te gee van die aard van so 'n grondleggende samehangsvisie, moet ons eers saaklik stilstaan by die grense van wetenskaplike begripsvorming. 'n Begrip kan omskryf word as 'n norm-bepaalde feitlike analitiese sin-figuur waarin onderskeie elemente analities geìmpliseer is wat in logiese oordele uitgelê kan word. (Indien oordele elemente ekspliseer wat nie analities in die betrokke begrip geimpliseer is nie, resulteer on-logiese oordele - oortreding van die logiese norm van non-kontrakdiksie.) Die geimpliseerde elemente wat analities in 'n begrip vervat is, is geidentifiseerde en onderskeie (dit wil sê logies geobjektiveerde) gegewens. Daar bestaan egter talle gegewens wat nie sélf logies geobjektiveer kan word nie, maar wat nietemin slegs met betrekking tot logies-geobjektiveerde gegewens geken kan word. (Die term „ken” (kennis), dui dus veel méér aan as blote begrips-kennis.)

Dít wat ons slegs kan ken in terme wat logies objektiveerbaar is, maar wat self logiese objektivering te bowe gaan, is derhalwe benaderbaar deur middel van 'n logiese objektiveringsaktiwiteit wat die denke verwys na gegewens wat buite die grense van logies begripsvorming val: daarvan kan 
hoogstens 'n grensbegrip, 'n idee gevorm word, wat na sy aard verwysend en rigtinggewend (regulatief) is. Die Bybel openbaar God byvoorbeeld met betrekking tot die skeppingsverskeidenheid wat logies objektiveerbaar is. maar verwys en rig die menslike denke daarmee in feite na iets wat alle begrip te bowe gaan en gevolglik slegs benader kan word in 'n Gods-idee. Selfs die tydelike identiteit van enige individuele skepsel kan slegs benader word in 'n rigtinggewende grensbegrip en word daarom in hierdie regulatiewe sin as veronderstelde benodig, alvorens oorgegaan kan word tot 'n teoretiese (dit is modaal-abstraherende) analise van die struktuur daarvan. Dieselfde geld ten opsigte van die onverbreeklike samehang waarin alle werklikheidsaspekte gevoeg is. Die kosmies-samehangende verskeidenheid aspekte en entiteite kan nooit in selfgenoegsaamheid in die skepping afgesluit word nie omdat dit slegs bestaan in afhanklike betrokkenheid op Christus in Wie alle dinge stand hou, en met verwysing na God Drie-enig as die Skepper van alle dinge (die skepping vertel immers die eer van God en verkondig die werk van sy hande).

Elke teoretiese analise van die verskeidenheid aspekte en tipiese strukture in die werklikheid behoort gevolglik regulatief onderlê te word deur ' $\mathrm{n}$ By. bels-gefundeerde skeppingsidee wat opgeneem is in die omvattend-grondleggende aard van 'n wysgerige grondidee waarin die samehang en verskeidenheid, die volheid (totaliteit) én die Oorsprong van alle dinge verantwoord word. (Vergelyk oor die probleem: Skepper - skepping (met wetsy en feitlike sy) versus God, wet en kosmos my artikel: God, wet en kosmos in die Skrifmatige Ontologie van BJ.van der Walt. Tydskrif vir Christelike Wetenskap, 1ste kw. 1977.)

Die wysgerige grondidee dien inderdaad as transendentale (grondleggende) voorwaarde van alle wetenskaplike denke, dit wil sê dit vorm die noodsaaklike teoretiese veronderstelling van teoreties-logiese denke in die sin dat dit laasgenoemde as sodanig eers móóntlik maak. Hierbenewens moet ons daarop wys dat die wysgerige grondidee, wat steeds 'n grondleggende teoretiese struktuur en funksie besit, sélf afhanklik is van en in die greep is van sentrale bo-teoretiese (in onderskeiding van voor-wetenskaplike of voorteoretiese) uitgangspunte wat aan die teoretiese denke sy alles-beheersende rigting gee, hetsy op God, hetsy in diens van die afval. Dit mag illustratief wees om op hierdie punt eers twee voorbeelde kortliks te vermeld.

\section{Voorbeeld I}

Die ontdekking van irrasionale getalle in die Griekse wiskunde

Die oudste Griekse wiskunde was in die eerste plek aritmetiek soos blyk 
uit die karakteristieke wysgerige grondidee: alles is getal. Volgens die Pythagoreërs vind alle orde en hamonie in die kosmos hul wortel in getal. Die sentrale grondmotief van die Griekse denke (later deur Aristoteles tuisgebring onder die benaming: vorm en materie) kan in hierdie stadium aangedui word as die begrensde en onbegrensde (peras en apeiron ... die ecrste van die tien teenstellinge van die Pythagoreërs). Uit die eenheid as oorsprong ontspring die getallereeks in sy onbegrensdheid (oneindigheid), wat tegelyk die kosmos begrens en maat en harmonie daarin teweegbring. Omdat alles in laaste instansie vir die Pythagoreërs getal is, het hulle saam met 'n ou Griekse opvatting geglo dat ook alle lynstukke in die verhouding van heelgetalle tot mekaar staan, dat dit met ander woorde 'n gemeenskaplike maat (ratio, logos) besit en derhalwe kommensurabel is. (Ons sou sê dat hulle van mening was dat die lengte van enige lynstuk deur 'n rasionale getal aangegee kon word.) Toe Ilippasos van Metapontum (450 v.C.) egter (uit die aard van 'n reëlmatige vyfhoek) ontdek dat daar irrasionale (in kommensurabele) getalle bestaan, is die vormgewende en begrensende funksie van getal ernstig ondergrawe: dit het geblyk dat die vormmatig-begrensde skuinssy, byvoorbeeld van ' $n$ reghoekige driehoek met twee reghoeksye van lengtemaat 1 , in sigself (aritmeties gesien) 'n oneindige (onbegrensde) reeks herberg. Met ander woorde: hier het die apeiron die begrensende funksie van die peras opgehef! Om hierdie konsekwensie te vermy, is 'n alternatiewe wysgerige grondidee ingevoer: alle algebraiese probleme (weliswaar het die Grieke nog geen algebra geken nie) is vertaal in ruimtelike terme waaruit die geometrisering van die wiskunde gevolg het. Hieruit is dit oorduidelik hoedat die grondmotief van die Griekse denke integraal bepalend was vir die hele rigting waarin die Griekse wiskunde ontwikkel het!

\section{Voorbeeld II}

Die kontinuiteitspostulaat van die humanistiese natuurwetenskapsideaal onder uiteenlopende grondnoemers in die moderne biologie

Die moderne (neo-Darwinistiese) fisikalistiese evolusionisme ag alle lewende dinge gerangskik in 'n struktuurlose genetiese kontinuum (bewerk deur die kombinasie van mutasie en natuurlike seleksie). Hierdie afstammingsidee is uitdruklik nominalisties (in onderskeiding van die platoniesbeinvloede idealistiese morfologie wat selfs vandag nog aanhangers in die biologie besit). Die natuurpool binne die humanistiese grondmotief van natuur en vryheid besit hier die onbetwiste voorrang - veral by dié neoDarwiniste wat alle egte menslike vryheid ophef in 'n fisikaal-determinis- 
tiese siening.

Die veronderstelde struktuurlose afstammingskontinuum hoef egter nie noodwendig onder 'n fisiese noemer tuisgebring te word nie. Hoewel die Duitse bioloog, R. Woltereck, 'n emergensic-evolusionis is, wil hy tog in die biotiese feitlike sy 'n grondnoemer vind vir die evolusieproses (weliswaar dialekties gemotiveer vanuit die humanistiese vryheidsmotief wat vashou aan die biologiese messiasverwagting van 'n skeppend-vrye menslike gees!) Ook die holistiese biologie van A. Meyer kies 'n biotiese grondnoemer vir die (sprongsgewys ontwikkelende) afstammingslyn. Veral aanhangers van die organismiese biologie probeer die afstammingskontinuiteit versoen met 'n biotiese noemer. In die pan-psigisme van die bekende Duitse dierkundige, B. Rensch, word die evolusionêre kontinuum (in deterministiese sin) onder 'n psigiese noemer gebring. Indien daar geen gapings (diskontinuiteite) in die evolusionêre afstammingslyn bestaan nie, moet laere diersoorte, plante en selfs die anorganiese sfeer sekere ooreenstemmende 'psigiese' komponente besit: "Here again it is difficult to assume the sudden origin of first psychic elements somewhere in this gradual ascent from non-living to living systems. It would not be impossible to ascribe 'psychic' components to the realm of inorganic systems also, i.e. to credit nonliving matter with some basic and isolated kind of 'parallel' processes" (Evolution above the species level, London, 1959, p. 342). Vanuit die vergoddelikte psigiese werklikheidsaspek word die ryk van stoflike dinge en die planteryk ook met sensitiewe vermoëns bekroon! (Vergelyk my artikel: Evolusionisme en die vraag na 'n grondnoemer, in: Woord en Wetenskap, Bloemfontein 1977, pp. 248-273.)

Teen die agtergrond van die behandelde onderskeidinge kan ons tans 'n gespesifiseerde inhoud aan die onderwerp van bespreking gee deur positief te stel:

\section{Die Skrif: inderdaad die lig vir alle wetenskappe!}

Indien dit waar is dat wetenskaplike denke teoreties-logiese (modaalabstraherende) denke is, is dit ook waar dat élke wetenskaplike kragtens die aard van sy wetenskaplike denke bewus of onbewus arbei op die basis van 'n samehangsidee (wysgerige grondidee) wat op sý beurt 'n sentrale bo-teoretiese stellingname benodig. Hierdie sentrale stellingname sal sy teoretiese denke rig via die transendentale grondidee. Die radikaal-Bybelse reformasie van alle wetenskappe is daarom ten diepste afhanklik van die vraag of die betrokke wetenskaplike in die greep is van die volle en omvattende appèl van Gods Woord. Hierdie Bybelse uitgangspunt van Christelike denke en wetenskap is ál waarvoor daar met reg onfeilbaarheid opge- 
eis kan word. Die Bybelboodskap is immers nie 'n menslike vindsel nie, maar 'n Christusgegewe in die herbore hart! Hoewel in beginsel verlos en vrygemaak tot die diens van God, ook in ons denkc en wetenskap, bly elke faset van die Christen-wetenskaplike arbeid egter voorlopig en feilbaar en derhalwe reformeerbaar!

Tog verg die Bybelse uitgangspunt van Christelike denke dat noulettend gewaak sal word teen die vergoddeliking van enige skepselgegewe. Só ' $n$ vergoddeliking (verabsolutering) is immers die direkte gevolg van die sondeneiging van ons hart (ook by die herbore Christen!) om iets in die skepping aan die almag van God te wil onttrek deur dit in vermeende absoluutheid op sigself te wil stel. Slegs in Christus word ons in beginsel van hierdie afvalweg bevry - belangrik juis in die wetenskap waar elke dissipline sy eie geskiedenis van -ismes (vergoddelikings) kan ten toon stel. Egte -ismes in die wetenskap is altyd ' $n$ kenteken van 'n verabsoluteerde grondnoemer in terme waarvan die ganse skeppingsverskeidenheid (reduserend) verklaar wil word. Uit hierdie eienskap blyk dit egter ook dat die (hartsbepaalde) keuse van 'n bepaalde samehangsvisie (verabsoluteerde grondnomer of die erkenning van geskapenheid van elke skepselgegewe na sy aard) allereers op teoretiese vlak na vore tree in wysgerige vorm. Slegs die wysbegeerte besit die taak om teoreties rekenskap te gee van die grondleggende skeppingsverskeidenheid waarop elke vakwetenskap steeds vanuit sy besondere en begrensde studiegebied deurlopend stuit. Selfs die vraag wát wetenskap is (soos toegespits op enige spesifieke vakwetenskap) kan nie vakwetenskaplik beantwoord word nie, want elke definisie van die studiegebied van 'n vakweten skap (die teologie ingesluit) sluit die betrokke definisie juis uit! (Daarom dat die dissipline: ensiklopedie van die teologie, ál die teologiese subdissiplines vermeld sonder om homself as één van die betrokke subdissiplines te klassifiseer.)

Die wysgerige gefundeerdheid van alle vakwetenskappe bevestig slegs dat die innerlike reformasie van alle vakwetenskappe slegs kan geskied langs die weg van 'n radikaal-Bybelse reformasie van die wysbegeerte. Onder meer as gevolg van die korte geskiedenis van reformatories-wysgerige denke, wat reeds verskillende variante met hul eie aksente opgelewer het, is dit begryplik dat ons nie ooroptimisties moet wees oor die ver-Christeliking van die bestaande verskeidenheid vakwetenskappe nie, al moet tegelyk daaraan toegevoeg word dat aanknopingspunte sekerlik reeds in alle vakwetenskappe bestaan - vertrekpunte wat in sommige vakwetenskappe reeds tot 'n geweldige gevorderde mate uitgewerk is. In werklikheid is die roeping wat op ons skouers binne die jonge reformatoriese tradisie geplaas word die volgende: om te midde van uiteenlopende aksente wat die wysgerige grondlegging be- 
tref, die geesgenootlike denkgemeenskap in stand te hou sodat daar inderdaad ook op vakwetenskaplike gebiede 'n duidelik-herkenbare Christelikwetenskaplike tradisie kan ontstaan waarop, in opeenvolgende geslagte, reformatories voortgebou kan word.

Juis omdat die reformatoriese inset van só 'n tradisie reeds dikwels in Christelike kringe vir my besef belemmer en ontkrag is deur 'n bepaalde gereformeerd-skolastiese siening van 'n 'lig van die Skrif' met betrekking tot sogenaamde Skrifbeginsels, wil ek nog eens ten slotte my standpunt negatief daarteenoor afgrens.

\section{Skrifbeginsels?}

Om enige misverstand oor die term ,beginsels" te vermy, is dit sinvol om allereers positiewe inhoud aan dié term te gee. 'n Beginsel kan ons saaklik omskryf as ' $n$ universele behorense is wat in sy taakstellende aard aan die menslike subjek 'n keusevryheid laat in sy toepassing (konkretisering, positivering) daarvan, maar wat tegelyk ook (as gevolg van die sondeval) oortree kan word.

Géén beginsel geld vanself nie - dit is steeds angewese op die mens as kultuurhistoriese maghebber om daar konkrete (eietydse) vorm aan te gee. Hierdie positivering kan òf in ooreenstemming, òf in stryd met die eise in die betrokke beginsel vervat, geskied. (Die oortreebaarheid van die Godgegewe skeppingsbeginsels - 'n moontlikheid wat met die sondeval werklikheid geword het - blyk duidelik uit die talle teenstellinge wat ons in die tipies menslike fasette van die skepping aantref: logies - on-logies; histories - on-histories; ekonomies - on-ekonomies; eties - on-eties; geloof - ongeloof, en so meer.)

Die fundamentele onderskeiding tussen beginsel en positivering is uiters noodsaaklik indien ontkom wil word aan die valstrikke van biblisisties-vermeende 'Skrifbeginsels'. Die biblisis is immers geneig om steeds bepaalde positiverings in die Ou en/of Nuwe Testament te wil verhef tot algemeengeldige beginsels, vergetende dat die besondere konkrete omstandighede van elke positivering in die algemeen veroorsaak dat $\mathrm{h}$ positivering $\mathrm{h}$ unieke historiese karakter besit en derhalwe nie sonder meer van toepassing gem aak kan word op alle ánder historiese omstandighede wat uiteraard daarvan sal verskil nie.

Die willekeur waarmee sekere positiveringe in die Bybel wél uitgelig en verhef word tot algemeen-geldige 'Skrifbeginsels' berus by nadere toesien op die volgende 'eksegetiese prosedure': Wanneer dit enigsins voorkom asof 'n bepaalde positivering in die Bybel (grootliks) ooreenstem met 'n positivering 
wat ons vandag nog ken. byvoorbeeld die monogame huwelik, word gekonkludeèr dat ons met ' $n$ 'Skrifbeginsel' te doen het. Al dáárdie positiveringe wat egter duidelik radikaal verskil van dit wat ons vandag ken, word sonder nadere verantwoording verontagsaam, hoewel ons dikwels nog gebind word aan positiveringe wat selfs in die Nuwe Testament agtergelaat is (vergelyk slegs die verskil tussen die Ou 'Testamentiese sabbatsheiliging en die viering van die Sondag in die nuwe bedeling). Omdat positiveringe in elke historiese tyd verskil, impliseer hierdie 'prosedure' tegelyk dat elke tyd sy eie Skrifbeginsels sal hê!

Sonder om hier nader in te gaan op die vraag hoe dit moontlik is om teoreties te kom tot die blootlegging van die grondleggende skeppingsbeginsels vir ons volle lewe, moet tog beklemtoon word dat skeppingsbeginsels geensins inhoudlose formules is nie. Die voortskryding van die Ou bedeling na die Nuwe bedeling staan juis in die teken van die feit dat God se heilsplan met die mensheid onder meer daarop gemik is om weerreens gestalte te gee aan ' $\mathrm{n}$ gehoorsaamheid aan dit wat God van skeppingsweë verorden het. Selfs die tien verbondswoorde moet daarom gesien word as die gepositiveerde verbondswil van God vir Israel wat voorafskaduend heenwys na die verlossing in Christus wat ons in beginsel sou vrymaak tot die diens van God met die hele hart, gehoorsaam aan Sy lewensomvattende skeppingswet. Juis dáärom is die verlossingsperspektief van die Bybel deurslaggewend vir die korrekte waardering van die sinryke normatiewe inhoud van Gods skeppingswet, want die verskeidenheid skeppingsbeginsels is gely klik saamgetrek in die eenheid en volheid van Gods wet, die sentrale liefdegebod. In hierdie sin bepaal die Bybel ons op Godgerigte insig in en gehoorsaamheid aan die skeppingsbeginsels wat vir alle lewensfasette gegee is.

Soms word gesê dat die inhoud van die Bybel (in die volle sentrale hartsappèl wat dit uitoefen op die mens) normerend is vir sy geloof (die Bybel word dan die norm vir die geloof genoem). Beteken dit dat die skepping geen geloofsnorme bevat nie omdat die norm van die geloof eers met die ontstaan van die Bybel gegee is? Hierdie vraagstelling kan ons praktiesintuitief met die volgende weervraag benader: Ervaar die Christen-gelowige dit as 'n normatiewe eis dat sy geloofslewe lewenskragtig en Godvrugtig moet wees, dat sy geloof geloofsoffers verg, dat sy geloofslewe geloofsensitiwiteit (gevoeligheid) eis, wat die teendeel is van gevoelsgodsdiens en dwepery, dat sy geloofslewe geloofsonderskeiding en -identifisering vra, dat die geloofsimboliek van hom korrekte geloofsinterpretasie verlang, dat hy daagliks die regte geloofstempo moet volhou en in 'n kontinue geloofstryd sy lewenswandel moet reformeer sodat hy steeds in geloofsharmonie en met $g e$. loofstrou en -regverdigheid as 'n geintegreerde gelowige voor God kan staan? 
Ek is oortuig daarvan dat élke Christen-gelowige sonder meer die normatiewe appèl van al hierdie beginsels vir sy geloofslewe sal ervaar - en tog betref hierdie beginsels die skeppingsgegewe moontlikhede wat tot die struktuur van die geloofsfaset van die werklikheid behoort en wat derhalwe in die ongeloof ook 'n afvallige en skeefgetrekte gestalte kan verwerf. 'n Teoretiese (transendentaal-empiriese) analise van die modale struktuur van die geloofsaspek toon immers dat elke onderstreepte koppelwoord die aanduiding is van 'n (teoreties-benaderde) retrosiperende modale skeppingsbeginsel vir ons geloofslewe! Omdat die omvattende orde van Gods skepping óók die geloofsaspek insluit, is dit duidelik dat ons onverkort moet handhaaf dat daar inderdaad geloofsnorme veranker is in die skepping!

Omdat daar telkens op hierdie punt 'n misverstand ontstaan (naamlik dat hierdie gedagte daarop neerkom dat die Bybel vervang word met die skeppingsorde en dat ' $n$ insig in die skeppingsbeginsel buiteom die Woordopenbaring verkry kan word), beklemtoon ons by herhaling dat die insig dát daar skeppingsbeginsels is, asook die blootlê of analisering daarvan, nooit buiteom of onafhanklik van die Bybel kan geskied nie, omdat slegs die Bybel aan ons openbaar dat God die Skepper van alle dinge is wat ook die mens onderwerp het aan die normerende wet wat Hy gestel het.

Aangesien die 'lig van die Skrif' wel die Christusherbore hart open in gerigtheid op die gehoorsaming van dït wat God van skeppingsweë verorden het, maar waaraan die mens as gevolg van die sondeval ongehoorsaam geword het, is dit prinsipieel verantwoord om (selfs teoreties) te besin oor die aard van skeppingsbeginsels. In sy gesprek met die Fariseërs het Christus hierdie faset duidelik belig. Nadat aangevoer is dat Moses wel 'n skeibrief gegee het, antwoord Christus dat dit as gevolg van die hardheid (sondig heid) van hul harte was en voeg dan daaraan toe dat dit nié van die begin af so was nie. In die begin het God hemel en aarde geskape - dit wil sê kragtens die skepping in die begin, kragtens die skeppingsbeginsel wat geld vir die huwelik is dit ongeoorloof om te skei, maar as gevolg van die sondeval het die mens in die posisie geland dat hierdie antinormatiewe moontlikheid werklikheid geword het.

Juis omdat die ontvouing van die Ou en Nuwe Testamentiese gebeure binne die orde van Gods skepping afspeel, spreek die Bybelse gehoorsaamheidsappèl telkens tot ons in die uiteenlopende gehoorsaamheidsgestaltes wat ons in die Ou en Nuwe Testament aantref, sonder dat die Bybel daarmee gelyktydig aan ons allerlei skeppingsbeginsels (in 'herdrukte' vorm as 'Skrifbeginsels') blootlê. Bykomend'moet ons beklemtoon dat die boodskap van die Bybel, in die volheid daarvan, normerend in die sin van bepalend is vir álle Christelike lewensuitinge van die mens en nie slégs vir sy 
engere godsdienstige en geloofslewe nie - die sentrale liefdegebod onderlê immers ons ganse Christelike lewensroeping. Sonder twyfel word die feitelike inhoud van ons Christelike geloof ook deur die Bybel in Christus aan ons besorg. Hier sou ons ook kon sê dat die Bybel die inhoud van ons Christelike geloof bepaal - 'n spreekwyse wat waarskynlik beter is as om te sê dat die Bybel die norm vir ons geloof is, omdat laasgenoemde uitdrukking in ons Protestantse tradisie so 'n sterk Gereformeerd-skolastiese verleidingskrag het - indien die Bybel die norm vir ons geloof is, word maklik die volgende tree gegee tot by die teoloog wat die 'Skrifbeginsels' moet uitdiep en deurgee aan die gelowige, want slegs só sou laasgenoemde in sy verskillende lewensaktiwiteite Christelik kon handel.

In die konteks van ons besinning oor die Skrif en die lig daarvan vir alle wetenskappe, sou hierdie Gereformeerd-skolastiese instelling onder meer impliseer dat die teoloog (of teologies-onderlegde predikant) die nodige 'Skrifbeginsels' moes deurgee wat ons wetenskaplike denke normeer. Met watter eksegetiese teksgimnastiek sou egter gekom kon word tot ' $\mathrm{n}$ 'Bybelse fundering' van die verskillende logiese norme wat wetenskaplike denke reguleer? Watter Bybeltekste bied 'n struktuuranalise van die modale aard van die logiese aspek of van die modale logiese beginsels (soos die logiese beginsels van identiteit, teëspraak, uitgeslote derde, toereikende grond, denkekonomie, en so meer)? Bloot die stel van hierdie vrae dui reeds die absurditeit en onvrugbaarheid van 'n konsekwente biblisistiese benadering aan.

Daarom is ek oortuig dat die effektiewe en sinvolle reformasie van álle wetenskappe slegs sal kan gedy indien ons konsekwent waak teen enige biblisistiese verskraling, en ons totale gehoorsaamheid betoon aan die lewensomvattende gehoorsaamheidsaanspraak van die Bybel, wat slegs in hierdie sentrale sin lig bied vir alle wetenskappe! 